\title{
Multiscale Study on the Modification Mechanism of Red Mud Modified Asphalt
}

\author{
Tao Fu, ${ }^{1}$ JianHui Wei $\mathbb{D},{ }^{1}$ Huiming Bao $\mathbb{D}^{2},{ }^{2}$ and Junlin Liang $\mathbb{C}^{1}$ \\ ${ }^{1}$ College of Civil Engineering and Architecture, Guangxi University, Nanning 530004, China \\ ${ }^{2}$ College of Civil Engineering and Architecture, Guilin University of Technology, Guilin 541004, China \\ Correspondence should be addressed to Huiming Bao; bhming@163.com and Junlin Liang; 1j1_1217@126.com
}

Received 6 May 2020; Revised 19 June 2020; Accepted 8 July 2020; Published 13 August 2020

Academic Editor: Yuqing Zhang

Copyright ( $\odot 2020$ Tao Fu et al. This is an open access article distributed under the Creative Commons Attribution License, which permits unrestricted use, distribution, and reproduction in any medium, provided the original work is properly cited.

Red mud, a waste residue of aluminium industry, was used as modified asphalt material to prepare red mud modified asphalt and red mud modified asphalt under freeze-thaw cycles. The matrix asphalt (MA), red mud modified asphalt (RMMA), and red mud modified asphalt under freeze-thaw cycles (RMMAFC) were studied by scanning electron microscopy (SEM), Fourier transform infrared spectrometry (FTIR), atomic force microscopy (AFM), and differential scanning calorimetry (DSC). Microscopic experiments were conducted to investigate the modification performance and mechanism. The modification mechanism of red mud modified asphalt was investigated using molecular dynamics simulation in this study. The results show that red mud can form a uniform and stable blending system with base asphalt after adding base asphalt. The structure of asphalt after adding red mud and adding red mud and freezing-thawing cycles does not change. The bee-structure decreases obviously with the addition of red mud by atomic force microscopy (AFM). Density decreases gradually, but bee-structure height increases obviously; beestructure of red mud modified asphalt is destroyed after freeze-thaw cycles. Through differential scanning calorimetry (DSC), after adding red mud, heat absorption decreases. Freeze-thaw cycles greatly reduce heat absorption of red mud modified asphalt. Constructing molecular model of major components of red mud $\left(\mathrm{Fe}_{2} \mathrm{O}_{3}, \mathrm{Al}_{2} \mathrm{O}_{3}\right)$ and asphaltene, simulation results show that the interfacial energy between asphaltene and red mud's main components $\mathrm{Fe}_{2} \mathrm{O}_{3}$ and $\mathrm{Al}_{2} \mathrm{O}_{3}$ at $-10^{\circ} \mathrm{C}, 25^{\circ} \mathrm{C}$, and $170^{\circ} \mathrm{C}$ is stronger than that of $\mathrm{Fe}_{2} \mathrm{O}_{3}$. The results of calculating the interfacial energy of asphaltene on the chemical composition surface of red mud are negative. It can be seen that there are adsorption effects on the surface of asphaltene and red mud. Therefore, increasing the content of $\mathrm{Al}_{2} \mathrm{O}_{3}$ or decreasing the content of $\mathrm{Fe}_{2} \mathrm{O}_{3}$ in red mud is beneficial to the adsorption of asphaltene.

\section{Introduction}

By the end of 2019, China's expressway has reached 4.85 million kilometers, ranking the first in the world. Asphalt pavement has gradually become the first choice of highgrade highway pavement in China due to its good smoothness, comfortable driving, and beautiful vision. However, in recent years, with the continuous increase of traffic load, rutting has gradually become one of the main damage types of asphalt pavement in China, and rutting damage of some roads is up to $30 \%$ [1]. Rutting has been listed as an independent detection index in the evaluation standard of highway technical condition, which shows the importance of rutting disease. Therefore, in the process of asphalt pavement design and construction, preventing the occurrence of rutting diseases is a key concern. The rutting disease is directly related to the high temperature performance of asphalt and mixtures. It has always been a hot spot of pavement material research to use different modifiers to improve the high temperature performance of asphalt and improve the rutting resistance of pavement [2-4]. In view of the shortcomings of asphalt performance, researchers in various countries have studied the modification of asphalt by adding modifiers [5].

Red mud is the industrial waste produced when alumina is extracted from aluminium industry. With the vigorous development of aluminium industry, the discharge of red mud is increasing, causing serious environmental disasters. 
So, the utilization of red mud is imminent [6]. Red mud has been widely used in metal precipitation, building materials, and environmental remediation [7-22]. In recent years, researchers have found that inorganic material modifier not only can improve the interface between asphalt and aggregate but also has the characteristics of simple production process, low price, excellent performance, and abundant reserves. Many researchers have used red mud as fillers [23]. Zhang and Sun et al. recognize the efficiency of red mud as mineral filler, three different filler materials, including limestone, hydrated lime, and fly ash, were selected and compared. It is indicated that the red mud increased the stiffness and elastic behavior of the corresponding asphalt mastic [24]. Zhang and Li et al. studied the influence of red mud on the properties of asphalt mortars and asphalt mixtures. It is indicated that the performance of porous asphalt with red mud filler at $0.9 \mathrm{FB}$ ratio exhibited enhanced performance for raveling and rutting resistance [25]. In order to study the interaction of red mud and asphalt further, the microtests of matrix asphalt (MA), red mud modified asphalt (RMMA), and red mud modified asphalt after freeze-thaw cycles (RMMAFC) are carried out, including scanning electron microscopy, Fourier transform infrared spectrometry (FTIR), and atomic force microscopy. Molecular dynamics simulation is introduced to analyze red mud modification at multi-scale. Asphalt and its modification mechanism were discussed.

\section{Material Properties}

\subsection{Experimental Design}

2.1.1. Material. AH-70 paving asphalt is obtained from Sinopec "Donghai" Branch of Maoming, Guangdong, China. The corresponding technical indexes meet the technical requirements of road petroleum asphalt (JTG F402004). The basic properties of the asphalt are shown in Table 1.

The red mud used is the industrial waste residue formed during the production of alumina by Bayer process in an alumina plant in Guangxi. It is a kind of highly alkaline $(\mathrm{pH}$ value is between 10 and 12.5), high content of $\mathrm{Fe}_{2} \mathrm{O}_{3}$ and $\mathrm{Al}_{2} \mathrm{O}_{3}$, and large compressibility cemented pore frame structure soil, with a particle size of only $0.088-0.25 \mathrm{~mm}$. The hydraulic components such as $\beta$-dicalcium silicate make it have solidification ability.

Snow-melting salt, which is the commonly used $\mathrm{NaCl}$ in projects, is produced by Xilong Chemical Industry, and its performance meets the requirements of GB/T 23851-2009 road deicing snow-melting agent.

2.1.2. Preparation of Red Mud Modified Asphalt. Red mud raw materials from the red mud yard are put into the oven and dried at $80^{\circ} \mathrm{C}$ for 24 hours. The red mud is ground to pass the $0.075 \mathrm{~mm}$ sieve by ball grinder. The modified asphalts were prepared using a high shear mixer. Asphalt was heated until it becomes a fluid at $170^{\circ} \mathrm{C}$. Then, red mud compound was added into asphalt and the mixture was blended at $4000 \mathrm{rpm}$ for 30 min (by testing the basic properties of red mud modified
TABLE 1: Technical properties of 70\# matrix asphalt.

\begin{tabular}{lcc}
\hline Technical indicators & Industry standard & Test results \\
\hline Penetration $\left(25^{\circ} \mathrm{C}\right)(0.1 \mathrm{~mm})$ & $60-80$ & 65.1 \\
Ductility $\left(15^{\circ} \mathrm{C}\right)(\mathrm{cm})$ & $\geq 100$ & 104.5 \\
Softening point $\left({ }^{\circ} \mathrm{C}\right)$ & $\geq 46$ & 48.5 \\
Flash point $\left({ }^{\circ} \mathrm{C}\right)$ & $\geq 260$ & 299 \\
Solubility $(\%)$ & $\geq 99.5$ & 99.88 \\
\hline
\end{tabular}

asphalt before, the optimum content of red mud is $11 \%)$. The freeze-thaw samples were prepared according to AASHTO283 Lottman test method. The material was taken out and put into a constant temperature environment at $25^{\circ} \mathrm{C}$. On the basis of the above preparation, the following operations were continued: (1) sampling was saturated with water for 4 minutes in vacuum; (2) sampling was frozen for 16 hours in a refrigerator at $-10^{\circ} \mathrm{C}$; and (3) sampling was taken out and bathed in an incubator at $60^{\circ} \mathrm{C}$ for 24 hours [24].

\subsubsection{Test Method}

(1) Differential Scanning Calorimetry. A DSC spectrometer (Zetzseh DSC204), produced in Germany, was used to determine the functional characteristics of asphalt in the experiment at a rate of $10^{\circ} \mathrm{C} / \mathrm{min}$, a nitrogen flow rate of $30 \mathrm{ml} / \mathrm{min}$, a starting temperature of $10^{\circ} \mathrm{C}$, and an ending temperature of $200^{\circ} \mathrm{C}$.

(2) Atomic Force Microscopy. AFM (Bruker Dimension ICON) was used to test MA, RMMA, and RMMAFC. In AFM experiment, a tiny (with a length of $125 \mu \mathrm{m}$, natural frequency of $70 \mathrm{kHz}$, and spring constant of $3 \mathrm{~N} / \mathrm{m}$ ) and spiky tip is attached at the unsupported end of a cantilever and kept close to an asphalt film. Due to close contact of the tips and the surface of the film, impulsive or attractive force between the atoms of top layer of asphalt and AFM is created which makes the deflection of the cantilever. The extent of the deflection absolutely depends on the developed force involving the molecules of the tips and the film.

(3) Scanning Electron Microscopy. SU5000 Scanning Electron Microscope (SEM) produced by Hitachi High-Technologies Corporation of Japan was used to test asphalt samples. The asphalt samples were treated by hot melting, cooled to room temperature, and then tested by spraying gold.

(4) Fourier Transform Infrared Spectroscopy. The instrument used in the experiment is Nicofe 7T40FTIR Fourier Transform Infrared Spectrometer made in the United States, which was used to determine the functional characteristics of asphalt in wavenumbers ranging from $400 \mathrm{~cm}^{-1}$ to $4000 \mathrm{~cm}^{-1}$.

\section{Results and Discussion}

3.1. Fourier Transform Infrared Spectrometric (FTIR) Analysis. The strength of the peak depends on the change of dipole moment when the molecule vibrates. The smaller the change of dipole moment, the weaker the band strength. 
Figure 1 shows that the absorption intensity of infrared spectrum peaks of base asphalt, RMMA, and RMMAFC are different. Table 2 shows the absorption position and vibration type of group, within the range of $3700-3100 \mathrm{~cm}^{-1}$ of functional group location, which was ascribed to the hydroxyl $(\mathrm{O}-\mathrm{H})$ vibrations. The absorption peak strength of base asphalt is greater than that of RMMA and RMMAFC, which indicates that the $\mathrm{O}-\mathrm{H}$ bond is reduced to a certain extent after adding modified asphalt to red mud, and the vibration effect of $\mathrm{O}-\mathrm{H}$ bond is weakened. Freeze-thaw cycles have little effect on $\mathrm{O}-\mathrm{H}$ bonds in red mud asphalt. The change of absorption peak strength in the vicinity of $1445 \mathrm{~cm}^{-1}$ mainly indicates the existence of hydroxyl groups in asphalt, and the peak value of modified asphalt after freeze-thaw cycles decreases slightly. The change of absorption peak intensity in the vicinity of $1035 \mathrm{~cm}^{-1}$ mainly indicates the change of the vibration frequency of sulfoxide $\mathrm{S}=\mathrm{O}$ functional group. In the range of $600 \mathrm{~cm}^{-1}$ to $950 \mathrm{~cm}^{-1}$, it is also called benzene ring substitution zone, the area where the aromatic components in asphalt are located. The substitution reaction occurs at different positions of benzene ring in the aromatic components. The change of absorption peak intensity indicates that substitution reaction may occur on benzene ring. The absorption peak intensity of base asphalt is stronger than that of freeze-thaw. The absorption peak strength of RMMAFC is higher than that of RMMA. The absorption peak strength of RMMAFC is slightly weakened, indicating that the aromatic content of red mud modified asphalt in freezing and thawing cycles is reduced. The functional groups of RMMA and RMMAFC were combination of functional of groups of MA. No new peaks appeared, which indicated that the red mud added into asphalt was mainly a physical adsorption, and no chemical reaction occurred.

\subsection{Scanning Electron Microscopic (SEM) Analysis.}

Through Figure 2, it can be seen from the scanning results of electron microscope that the surface of matrix asphalt is very uniform and belongs to homogeneous structure. For RMMA (Figure 3), the mixing of red mud powder and base asphalt still belongs to two-phase structure. Red mud powder is distributed in asphalt in the form of flake. Because the particle size of red mud powder is small and the specific surface area is large, there is a large surface energy among the red mud particles. At the same time, red mud powder absorbs part of the oil in asphalt to produce adsorption effect, resulting in partial swelling and overlapping phenomenon. The addition of red mud powder changes the composition of asphalt: the oil content in asphalt is an important reason for the fluidity of asphalt, and the wax in asphalt will cause the asphalt to become soft at high temperature and brittle at low temperature. Red mud absorbs part of the oil in the asphalt, resulting in the relative decrease of free wax content in the asphalt; thus the high temperature stability of the modified asphalt is increased; the decrease of oil content in the asphalt means that the relative content of asphaltene and gum is increased, the asphaltene determines the viscosity and stability sensitivity of the asphalt material, and gum determines

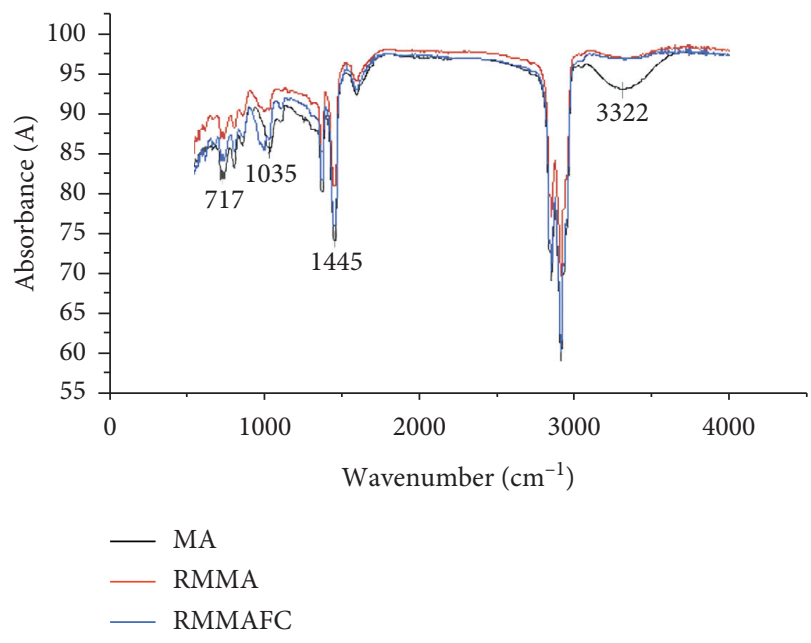

FIgURE 1: FTIR spectra of asphalt samples.

TABle 2: Group absorption position and vibration type.

\begin{tabular}{lcc}
\hline $\begin{array}{l}\text { Wavenumber } \\
\left(\mathrm{cm}^{-1}\right)\end{array}$ & $\begin{array}{c}\text { Functional } \\
\text { group }\end{array}$ & Vibration type \\
\hline 3322 & $\mathrm{O}-\mathrm{H}$ & $\begin{array}{c}\text { Stretching vibration } \\
\text { In-plane deformation } \\
\text { vibration }\end{array}$ \\
1445 & $\mathrm{C}-\mathrm{C}$ & $\begin{array}{c}\text { Oxidation reaction } \\
1035\end{array}$ \\
717 & $\mathrm{~S}=\mathrm{O}$ & Vibration absorption peak \\
\hline
\end{tabular}

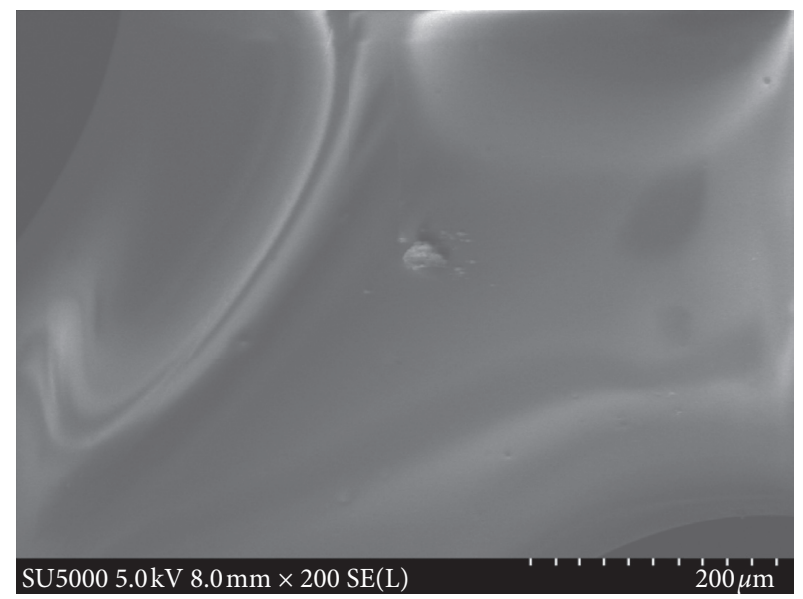

Figure 2: MA by electron microscopy.

the ductility of the asphalt material. With the increase of the relative content of asphaltene and gum, the temperature sensitivity of modified asphalt is increased correspondingly. For RMMAFC (Figure 4), a large number of salt grains appear in the image, and the volume is large, which seriously damages the asphalt membrane. The modulus of red mud particles at low temperature is higher than that of asphalt matrix, which can produce high stress concentration and induce a large number of craze and shear band. The generation and development of craze and shear band consume a lot of energy, so it can improve the modulus of low temperature corresponding to the glass transition temperature and ensure the flexibility of asphalt at low temperature. 


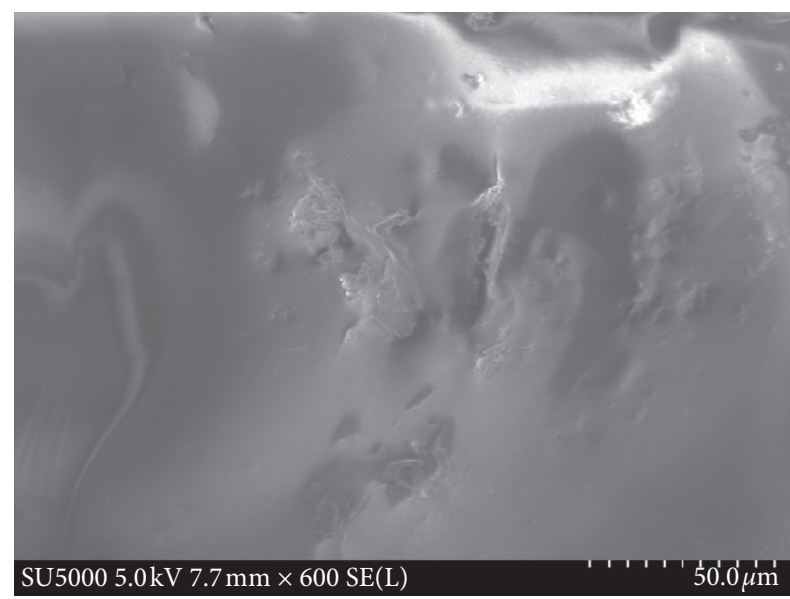

Figure 3: RMMA by electron microscopy.

3.3. Atomic Force Microscopic (AFM) Analysis. Figures 5-7 show AFM plots of MA, RMMA, and RMMAFC at room temperature. From the AFM diagram of asphalt, it can be seen that the bee-structure of base asphalt is dense. The bee-structure decreases obviously with the addition of red mud, and the density of bee-structure decreases gradually, but the bee-structure height increases obviously. The bee-structure of RMMAFC is destroyed and its distribution is not uniform. The polarity of asphalt mainly comes from heterocyclic atoms in asphalt; the bee-structure is mainly affected by the polarity of asphalt. The asphaltene micelles in asphalt are not completely dispersed in the medium, and the continuous phase is less. After adding red mud powder, the bee-structure in asphalt presents a long and large form, and the continuous phase increases. This is because after adding red mud powder to base asphalt, the light components in asphalt combine with red mud to form macromolecule, which results in the change of the relative content of asphalt components, thus affecting the temperature sensitivity of asphalt. Compared with the RMMA and RMMAFC, the beestructure in asphalt area and dense are decreased. After freeze-thaw cycle, red mud particles diffuse in asphalt to form smaller aggregates. The content of components continues to change, in which the light components are dispersed from the original structure under freeze-thaw action and fused with small aggregates to form a new aggregate. At the same time, due to the action of salt solution, the light components of modified asphalt become more, which results in the weakening of the direct connection effect between red mud powder and asphalt matrix, resulting in asphalt. The temperature sensitivity becomes more sensitive and the low temperature performance decreases.

In order to quantitatively characterize the roughness of base asphalt, RMMA, and RMMAFC, the image information of asphalt by AFM was further analyzed and counted. The high root mean square roughness, arithmetic mean deviation roughness, and peak coefficient were selected as the characteristic parameters to evaluate the surface of asphalt. Relevant information of base asphalt, RMMA, and RMMAFC was extracted and analyzed. The results are shown in Table 3. Generally speaking, the surface roughness

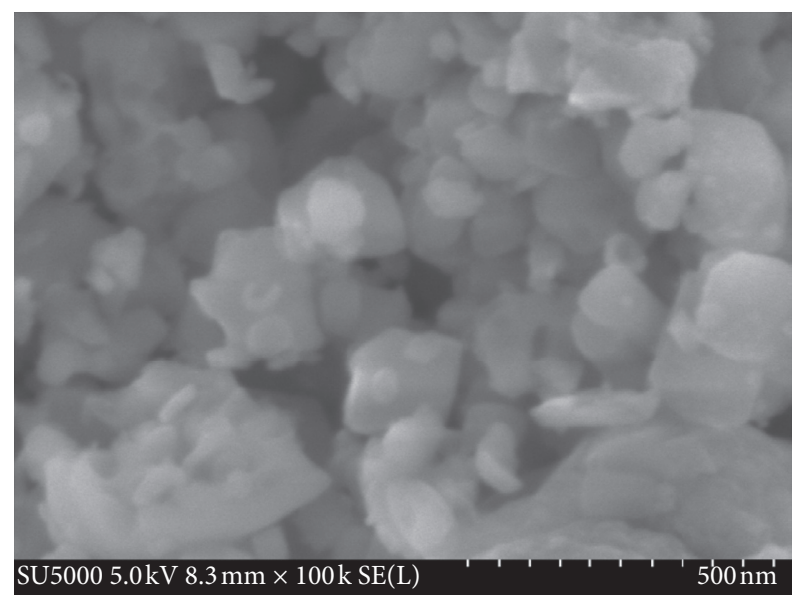

FigURE 4: RMMAFC by electron microscopy.

of RMMA is higher than that of MA and that of RMMAFC. For the index of peak coefficient, usually when the peak coefficient is less than 3, there are many peaks and valleys in the image surface morphology; when the peak coefficient is more than 3 , it shows that the image surface morphology is flat and there are not too many peaks and valleys. Combining with the morphology of AFM, the bee-structure decreases obviously with the addition of red mud, and the density of bee-structure decreases gradually, but the beestructure height increases obviously. This is due to the swelling effect of red mud added into asphalt, which is caused by the adsorption of free components in asphalt by red mud particles. The bee-structure of RMMAFC is destroyed and its distribution is not uniform. The red mudasphalt matrix structure is destroyed after freeze-thaw cycles, resulting in poor connection between red mud and asphalt, which also leads to a decline in the performance of RMMA.

\subsection{Differential Scanning Calorimetric (DSC) Analysis Based} on Molecular Dynamics Simulation. Taking base asphalt, RMMA, and RMMAFC as examples, we can conclude from Table 4 that the properties of RMMA and MA are roughly the same, while RMMAFC has obvious differences. The total endothermic peak energy of MA is $4.308 \mathrm{~J} / \mathrm{g}$, RMMA is $3.750 \mathrm{~J} / \mathrm{g}$, and RMMAFC is $1.281 \mathrm{~J} / \mathrm{g}$. The smaller the endothermic peak energy is, the more stable the properties of asphalt are. It can be seen from the degree and width of peak that the heat absorption of asphalt is reduced and the peak temperature is increased after red mud modification. The thermal stability of asphalt is improved after red mud modification, and the rheological properties of asphalt are also changed, so that the temperature sensitivity of asphalt is reduced. From the point of view of optimizing the performance of asphalt materials, it is necessary to delay the thermal diffusion speed of asphalt molecules. This requires reducing the free volume of asphalt materials, which can be achieved by adding inorganic materials or some macromolecule materials, so as to increase the "stiffness" of asphalt materials structure to a certain extent and to make asphalt materials. The large voids in asphalt become smaller, which 


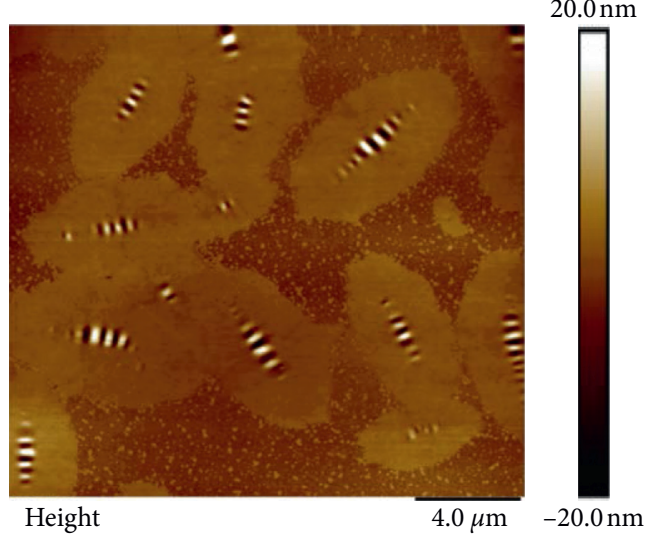

(a)

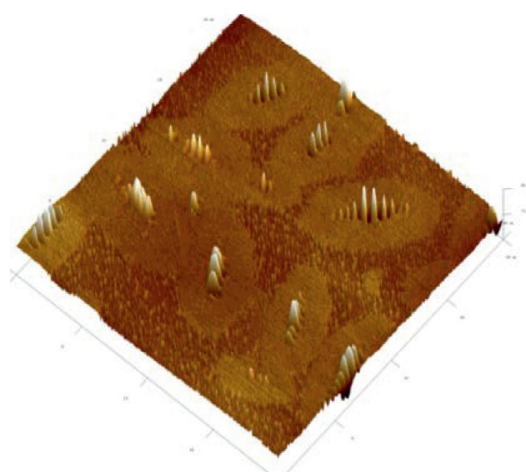

(b)

Figure 5: AFM of MA.

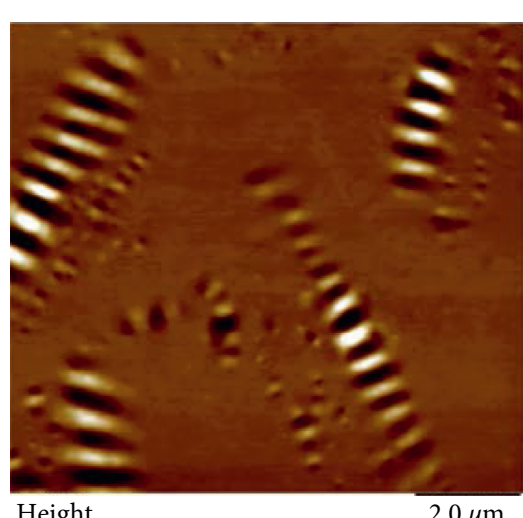

Height

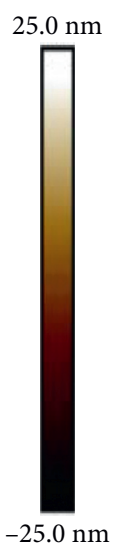

(a)

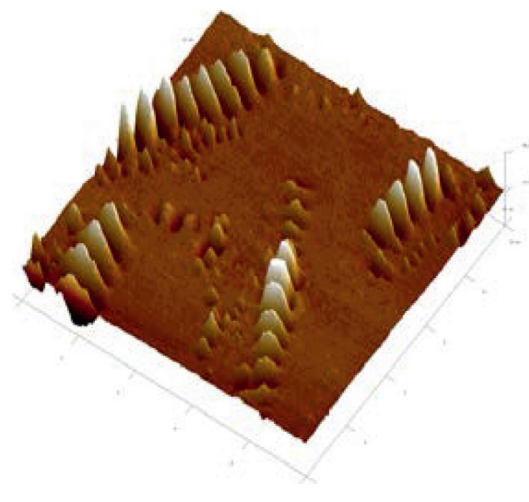

(b)

Figure 6: AFM of RMMA.


(a)

(b)

Figure 7: AFM of RMMAFC. 
TABLE 3: Asphalt AFM image parameters analysis.

\begin{tabular}{lccc}
\hline Type & $R_{q}(\mathrm{~nm})$ & $R_{a}(\mathrm{~nm})$ & Kurtosis \\
\hline MA & 2.10 & 1.71 & 25.7 \\
RMMA & 4.86 & 2.49 & 24.2 \\
RMMAFC & 1.50 & 0.94 & 14.9 \\
\hline
\end{tabular}

$R_{q}$ : a root mean square roughness parameter; $R_{a}$ : an arithmetic mean roughness; kurtosis: peak coefficient.

TABLE 4: Test results of state transition process of asphalt.

\begin{tabular}{lccccccc}
\hline Asphalt & $\begin{array}{c}\text { Heat absorption } \\
\left(\mathrm{J} \cdot \mathrm{g}^{-1}\right)\end{array}$ & $\begin{array}{c}\text { Peak } \\
\text { temperature }\left({ }^{\circ} \mathrm{C}\right)\end{array}$ & $\begin{array}{c}\text { Peak width } \\
\left({ }^{\circ} \mathrm{C}\right)\end{array}$ & $\begin{array}{c}\text { Heat absorption } \\
\left(\mathrm{J} \cdot \mathrm{g}^{-1}\right)\end{array}$ & $\begin{array}{c}\text { Peak } \\
\text { temperature }\left({ }^{\circ} \mathrm{C}\right)\end{array}$ & $\begin{array}{c}\text { Peak width } \\
\left({ }^{\circ} \mathrm{C}\right)\end{array}$ & $\begin{array}{c}\text { Total heat } \\
\text { absorption }\left(\mathrm{J} \cdot \mathrm{g}^{-1}\right)\end{array}$ \\
\hline MA & 1.457 & -15.15 & $-29.26 \sim 5.1$ & 2.851 & 19.12 & $5.1 \sim 43.67$ & 4.308 \\
RMMA & 1.119 & -15.80 & $-29.06 \sim 4.76$ & 2.631 & 19.19 & $4.76 \sim 43.86$ & 3.750 \\
RMMAFC & 0.290 & -19.99 & $-20.67 \sim-3.87$ & 0.991 & 29.86 & $22.37 \sim 54.21$ & 1.281 \\
\hline
\end{tabular}

restricts the synergistic movement of molecular chains in asphalt and achieves the purpose of reducing the thermal motion range of asphalt molecules.

\subsection{Analysis of Red Mud-Asphalt Interface Energy Based on} Molecular Dynamics Simulation. In this paper, the interface model of asphaltene molecule on red mud surface was constructed by molecular simulation software (materials studio). The adsorption energy of red mud modified asphalt at mixing temperature and before and after freeze-thaw was studied by molecular dynamics simulation.

The models of asphaltene molecule (Figure 8) on two main components of red mud, $\mathrm{Fe}_{2} \mathrm{O}_{3}$ and $\mathrm{Al}_{2} \mathrm{O}_{3}$, were established at $-10^{\circ} \mathrm{C}, 25^{\circ} \mathrm{C}$, and $170^{\circ} \mathrm{C}\left(-10^{\circ} \mathrm{C}\right.$ is the temperature in freeze-thaw cycles, $25^{\circ} \mathrm{C}$ is the indoor temperature, and $170^{\circ} \mathrm{C}$ is the heating temperature of asphalt). Through the building tool in Materials Studio toolbar, the crystal plane of $(0,0,1)$ is cut, then several layers of thickness are superimposed according to different chemical composition, and the crystal plane is optimized by Geometry Optimization geometry structure optimization tool in Forcite module. At the same time, energy is selected before the optimization of crystal plane is carried out. The cell compass force field parameters are given by the necklace. Under the NVT ensemble condition, the optimized interface model performs 200 PS dynamic calculation. Given the initial position as a random distribution, the simulated temperatures are $-10^{\circ} \mathrm{C}, 25^{\circ} \mathrm{C}$, and $170^{\circ} \mathrm{C}$. The Andersen temperature control method is used to control the temperature with a time step of $1.0 \mathrm{fs}$. Finally, a unit of $\mathrm{Fe}_{2} \mathrm{O}_{3}$ and an asphaltene, with lattice parameters of $a=b=30.21 \AA$ and $c=43.1255 \AA$ was used. As for the $\mathrm{Al}_{2} \mathrm{O}_{3}$ and an asphaltene, a unit cell with dimension of $a=b=57.108 \AA$ and $c=8.660667 \AA$ was used. The final bi-materials interface between asphaltene and two main components of red mud $\left(\mathrm{Fe}_{2} \mathrm{O}_{3}\right.$ and $\left.\mathrm{Al}_{2} \mathrm{O}_{3}\right)$ was built as shown in Figure 9.

Therefore, after the dynamic calculation of the interface model of asphaltene system on the chemical composition surface of red mud, the possible parameters of the interface can be obtained by the potential energy

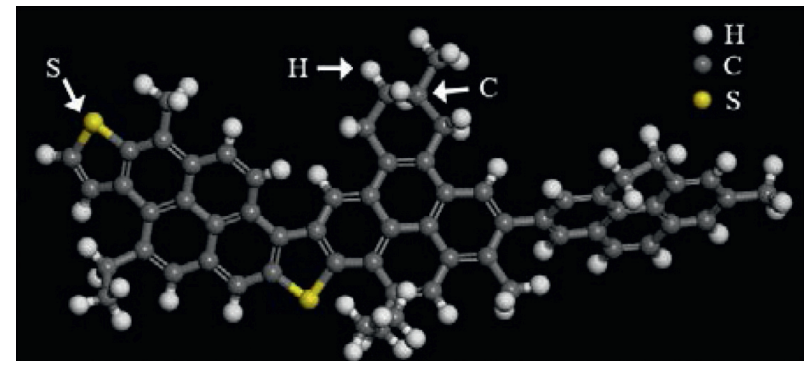

Figure 8: Asphaltene molecular structure.

calculation of each system of the interface model in turn $[25,26]$. However, in the process of dynamic simulation, the adsorption model with the lowest energy is needed first, because the model with the lowest energy is usually considered as the optimal model of adsorption state, and the formula for calculating the interfacial interaction energy is as follows:

$$
\Delta E=E_{\text {interaction }}=E_{\text {total }}-\left(E_{\text {surface }}+E_{\text {asphalt }}\right),
$$

where $E_{\text {surface }}$ is the total energy of the system when the lowest energy reaches the stable state after dynamics, $E_{\text {asphalt }}$ is obtained by deleting the chemical composition of the underlying aggregate and calculating the retained asphaltene, and $\Delta E$ represents the interaction energy between oxide interface and asphaltene interface.

According to literature [26], the greater the negative value of the interaction energy $\Delta E$ between the chemical composition of red mud and asphaltene in characterizing the stability of the adsorption system, the greater the interaction between the chemical composition of red mud and asphaltene and the stronger the adsorption of asphaltene on the surface of the chemical composition of red mud. On the contrary, if $\Delta E$ is 0 or positive, it indicates that asphaltene has little or no adsorption on the surface of red mud chemical composition.

From Table 5, the following can be concluded:

(1) When asphaltene is in contact with the surface of chemical composition of $\mathrm{Fe}_{2} \mathrm{O}_{3}$ and $\mathrm{Al}_{2} \mathrm{O}_{3}$, the results of interfacial interaction energy are negative, which indicates that there must be some adsorption between asphaltene and the surface of chemical composition of $\mathrm{Fe}_{2} \mathrm{O}_{3}$ and $\mathrm{Al}_{2} \mathrm{O}_{3}$. 


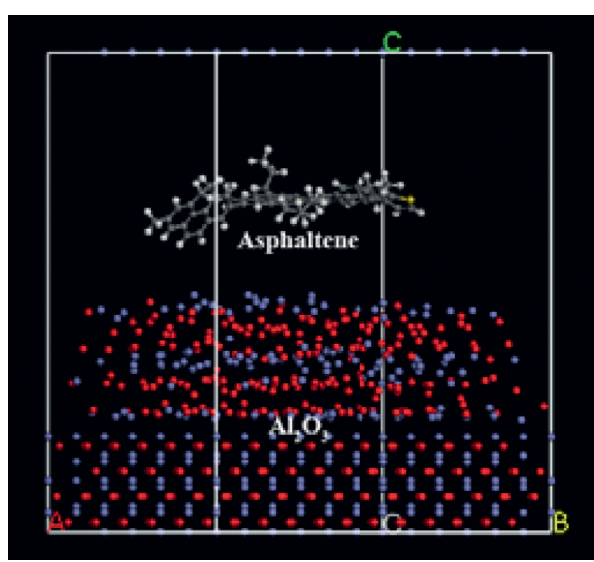

(a)

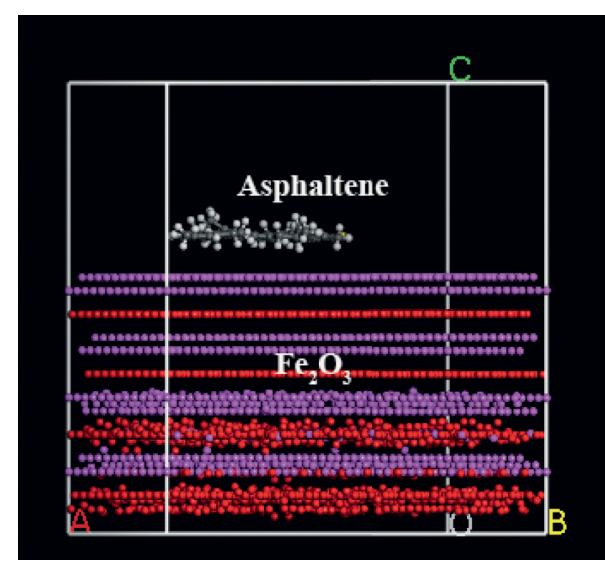

(b)

Figure 9: $\mathrm{Al}_{2} \mathrm{O}_{3}$ and $\mathrm{Fe}_{2} \mathrm{O}_{3}$ adsorbed asphalt.

(2) Adsorption energy of asphaltene on the surface of $\mathrm{Al}_{2} \mathrm{O}_{3}$ is the lowest at $25^{\circ} \mathrm{C}$, followed by $-10^{\circ} \mathrm{C}$ and $170^{\circ} \mathrm{C}$. The adsorption capacity of asphaltene on the surface of $\mathrm{Fe}_{2} \mathrm{O}_{3}$ is the lowest at $-10^{\circ} \mathrm{C}$, and the adsorption capacity is the highest at $25^{\circ} \mathrm{C}$, followed by $170^{\circ} \mathrm{C}$.

(3) The interfacial energy on the surface of $\mathrm{Fe}_{2} \mathrm{O}_{3}$ is relatively small, and the difference is not significant, but, on the surface of $\mathrm{Al}_{2} \mathrm{O}_{3}$, the interfacial energy is very obvious, showing strong adsorption.

The results of calculating the interfacial energy of asphaltene on the chemical composition surface of red mud are negative. According to the meaning of the formula of calculating the interfacial energy, it can be seen that there are adsorption effects on the surface of asphaltene and red mud. Through the above analysis, for red mud modified asphalt, $\mathrm{Al}_{2} \mathrm{O}_{3}$ in red mud provides a large number of adsorption interfaces for asphaltene, while $\mathrm{Fe}_{2} \mathrm{O}_{3}$ in red mud contributes less to this part. Secondly, in low temperature environment, the adsorption effect of asphaltene in $\mathrm{Fe}_{2} \mathrm{O}_{3}$ and $\mathrm{Al}_{2} \mathrm{O}_{3}$ is weaker than that in normal temperature. Therefore, increasing the content of $\mathrm{Al}_{2} \mathrm{O}_{3}$ or decreasing the content of $\mathrm{Fe}_{2} \mathrm{O}_{3}$ in red mud is beneficial to the adsorption of asphaltene. The simulation studies the change of interfacial energy between asphaltene and red mud. The research findings promote the fundamental understanding of modification mechanism on the chemophysical and chemomechanical relationships of asphalt. Further work will focus on simulation of physical reaction by three components and four components of asphalt materials using an integrated computational and experimental approach.

\section{Conclusion}

Red mud was used as modified asphalt material to prepare red mud modified asphalt and RMMAFC. The MA, RMMA, and RMMAFC were studied by scanning electron microscopy (SEM), Fourier transform infrared spectrometry (FTIR), atomic force microscopy (AFM), and differential
TABLE 5: Interfacial energy of asphaltene in oxides.

\begin{tabular}{lccc}
\hline \multirow{2}{*}{ Oxides } & \multicolumn{4}{c}{ Interfacial energy $E_{\text {interaction }}(\mathrm{kcal} / \mathrm{mol})$} \\
& $-10^{\circ} \mathrm{C}$ & $25^{\circ} \mathrm{C}$ & $170^{\circ} \mathrm{C}$ \\
\hline $\mathrm{Fe}_{2} \mathrm{O}_{3}$ & -1.772 & -2.214 & -2.265 \\
$\mathrm{Al}_{2} \mathrm{O}_{3}$ & -319.272 & -321.809 & -311.752 \\
\hline
\end{tabular}

scanning calorimetry (DSC). Microscopic experiments were conducted to investigate the modification performance and mechanism. The modification mechanism of red mud modified asphalt was investigated using molecular dynamics simulation in this study. The results can be summarized as follows.

(1) Fourier transform infrared spectrometric (FTIR) analysis of MA, RMMA, and RMMAFC shows that no new endothermic peaks are produced in Fourier transform infrared spectrometry (FTIR) and the position of characteristic endothermic peaks does not show obvious displacement, indicating that no new functional groups are produced, and the addition of red mud is not related to base asphalt. Chemical changes occur, but there was a physical blending process. According to the results of scanning electron microscopy, red mud as a modifier is uniformly fractionated in the asphalt in an independent form. Differential scanning calorimetric (DSC) analysis showed that the heat absorption peak and heat absorption of modified asphalt decreased after red mud modification, which indicated that the thermal stability of modified asphalt was improved and the temperature sensitivity was reduced. The heat absorption of modified asphalt with red mud was greatly reduced by freeze-thaw cycle.

(2) Atomic force microscopic (AFM) experiments show that the three asphalts have bee-structure. With the addition of red mud, the bee-structure decreases obviously, and the density of bee-structure decreases gradually, but the bee-structure height increases obviously. After freeze-thaw cycle, the bee-structure of RMMA is destroyed, its distribution is uneven, 
and the red mud-asphalt matrix structure is destroyed, resulting in the poor connection between the two.

(3) The results of calculating the interfacial energy of asphaltene on the chemical composition surface of red mud are negative. It can be seen that there are adsorption effects on the surface of asphaltene and red mud. With the help of molecular dynamics simulation, the interfacial energy between asphaltene and red mud main components $\mathrm{Fe}_{2} \mathrm{O}_{3}$ and $\mathrm{Al}_{2} \mathrm{O}_{3}$ at $-10^{\circ} \mathrm{C}, 25^{\circ} \mathrm{C}$, and $170^{\circ} \mathrm{C}$ is stronger than that of $\mathrm{Fe}_{2} \mathrm{O}_{3}$. Therefore, increasing the content of $\mathrm{Al}_{2} \mathrm{O}_{3}$ or decreasing the content of $\mathrm{Fe}_{2} \mathrm{O}_{3}$ in red mud is beneficial to the adsorption of asphaltene.

\section{Data Availability}

All data, models, and codes generated or used during the study are included within the article.

\section{Conflicts of Interest}

The authors declare no conflicts of interest.

\section{Acknowledgments}

This research was supported by grants from National Natural Science Foundation of China (Grants nos. 51368015 and 51768016) and Innovation Project of Guangxi Graduate Education, China (YCSW2020043).

\section{References}

[1] S. Hussan, M. A. Kamal, I. Hafeez, N. Ahmad, S. Khanzada, and S. Ahmed, "Modelling asphalt pavement analyzer rut depth using different statistical techniques," Road Materials and Pavement Design, vol. 21, no. 1, pp. 117-142, 2020.

[2] D. A. Gama, J. M. Rosa Júnior, T. J. A. de Melo, and J. K. G. Rodrigues, "Rheological studies of asphalt modified with elastomeric polymer," Construction and Building $\mathrm{Ma}$ terials, vol. 106, pp. 290-295, 2016.

[3] Q. Zhang, Y.-h. Xu, and Z.-g. Wen, "Influence of water-borne epoxy resin content on performance of waterborne epoxy resin compound SBR modified emulsified asphalt for tack coat," Construction and Building Materials, vol. 153, pp. 774-782, 2017.

[4] H. Yu, Z. Leng, Z. Zhou, K. Shih, F. Xiao, and Z. Gao, "Optimization of preparation procedure of liquid warm mix additive modified asphalt rubber," Journal of Cleaner Production, vol. 141, pp. 336-345, 2017.

[5] C. Fang, R. Yu, S. Liu, and Y. Li, "Nanomaterials applied in asphalt modification: a review," Journal of Materials Science \& Technology, vol. 29, no. 7, pp. 589-594, 2013.

[6] M. Mišík, I. T. Burke, M. Reismüller et al., "Red mud a byproduct of aluminum production contains soluble vanadium that causes genotoxic and cytotoxic effects in higher plants," Science of the Total Environment, vol. 493, pp. 883-890, 2014.

[7] D. Dodoo-Arhin, R. A. Nuamah, B. Agyei-Tuffour, D. O. Obada, and A. Yaya, "Awaso bauxite red mud-cement based composites: characterisation for pavement applications," Case Studies in Construction Materials, vol. 7, pp. 45-55, 2017.
[8] I. Panda, S. Jain, S. K. Das, and R. Jayabalan, "Characterization of red mud as a structural fill and embankment material using bioremediation," International Biodeterioration \& Biodegradation, vol. 119, pp. 368-376, 2017.

[9] H. Wang, B. Behnia, W. G. Buttlar, and H. Reis, "Development of two-dimensional micromechanical, viscoelastic, and heterogeneous-based models for the study of block cracking in asphalt pavements," Construction and Building Materials, vol. 244, p. 118146, 2020.

[10] Z. Li, J. Zhang, S. Li, Y. Gao, C. Liu, and Y. Qi, "Effect of different gypsums on the workability and mechanical properties of red mud-slag based grouting materials," Journal of Cleaner Production, vol. 245, p. 118759, 2020.

[11] T. Hertel and Y. Pontikes, "Geopolymers, inorganic polymers, alkali-activated materials and hybrid binders from bauxite residue (red mud)-putting things in perspective," Journal of Cleaner Production, vol. 258, p. 120610, 2020.

[12] W. Hu, Q. Nie, B. Huang, X. Shu, and Q. He, "Mechanical and microstructural characterization of geopolymers derived from red mud and fly ashes," Journal of Cleaner Production, vol. 186, pp. 799-806, 2018.

[13] R. Chen, G. Cai, X. Dong, D. Mi, A. J. Puppala, and W. Duan, "Mechanical properties and micro-mechanism of loess roadbed filling using by-product red mud as a partial alternative," Construction and Building Materials, vol. 216, pp. 188-201, 2019.

[14] Y. Zhao, N. Liang, H. Chen, and Y. Li, "Preparation and properties of sintering red mud unburned road brick using orthogonal experiments," Construction and Building Materials, vol. 238, p. 117739, 2020.

[15] J. Yang, D. Zhang, J. Hou, B. He, and B. Xiao, "Preparation of glass-ceramics from red mud in the aluminium industries," Ceramics International, vol. 34, no. 1, pp. 125-130, 2008.

[16] Z. Zhao, F. Xiao, and S. Amirkhanian, "Recent applications of waste solid materials in pavement engineering," Waste Management, vol. 108, pp. 78-105, 2020.

[17] S. Liu, Z. Li, Y. Li, and W. Cao, "Strength properties of Bayer red mud stabilized by lime-fly ash using orthogonal experiments," Construction and Building Materials, vol. 166, pp. 554-563, 2018.

[18] M. A. Khairul, J. Zanganeh, and B. Moghtaderi, "The composition, recycling and utilisation of Bayer red mud," Resources, Conservation and Recycling, vol. 141, pp. 483-498, 2019.

[19] S. Çoruh and O. N. Ergun, "Use of fly ash, phosphogypsum and red mud as a liner material for the disposal of hazardous zinc leach residue waste," Journal of Hazardous Materials, vol. 173, no. 1-3, pp. 468-473, 2010.

[20] J. Zhang, P. Li, M. Liang et al., "Utilization of red mud as an alternative mineral filler in asphalt mastics to replace natural limestone powder," Construction and Building Materials, vol. 237, p. 117821, 2020.

[21] X. Chen, Y. Guo, S. Ding et al., "Utilization of red mud in geopolymer-based pervious concrete with function of adsorption of heavy metal ions," Journal of Cleaner Production, vol. 207, pp. 789-800, 2019.

[22] E. Mukiza, L. Zhang, X. Liu, and N. Zhang, "Utilization of red mud in road base and subgrade materials: a review," Resources, Conservation and Recycling, vol. 141, pp. 187-199, 2019.

[23] J. Zhang, S. Liu, Z. Yao et al., "Environmental aspects and pavement properties of red mud waste as the replacement of mineral filler in asphalt mixture," Construction and Building Materials, vol. 180, pp. 605-613, 2018. 
[24] Y. Wang, J. Ye, Y. Liu, X. Qiang, and L. Feng, "Influence of freeze-thaw cycles on properties of asphalt-modified epoxy repair materials," Construction and Building Materials, vol. 41, pp. 580-585, 2013.

[25] G. Xu and H. Wang, "Molecular dynamics study of oxidative aging effect on asphalt binder properties," Fuel, vol. 188, pp. 1-10, 2017.

[26] G. Xu and $\mathrm{H}$. Wang, "Study of cohesion and adhesion properties of asphalt concrete with molecular dynamics simulation," Computational Materials Science, vol. 112, pp. 161-169, 2016. 